\title{
Reforma Agrária \\ A proposta é uma coisa, \\ o plano do governo é outra
}

ENTREVISTA

STU D OS A VA N ÇA D os reproduz a seguir entrevista do economista J osé J uliano de Carvalho Filho, professor da Faculdade de E conomia e Administração da U SP, publicada no número 22 (ano VI, jan/ fev, 2004) da revista Sem Terra, do M ST (M ovimento dos Trabalhadores Rurais Sem Terra).

EM PRIMEIRO LUGAR devo esclarecer que colaborei na elaboração da Proposta de Plano N acional de R eforma Agrária no grupo de técnicos formado pelo Dr. Plínio de Arruda Sampaio. Este fato possibilita responder com segurança por essa proposta e não pelo PNRA oficial do governo L ula. Comparar a nossa proposta e o PN RA do governo torna-se difícil porque, até onde eu saiba, ainda não existe um documento oficial. O que existe, até o momento, é o que foi exposto no Fórum $\mathrm{N}$ acional pela R eforma A grária e J ustiça no C ampo em Brasília e alguns documentos que recebi pela I nternet. D esses, apenas dois são oficiais. R efiro-me ao boletim do governo "em questão" - "País ganha novo Plano de R eforma Agrária" (uma página e meia) e ao documento do M D A "Plano N acional de Reforma Agrária" (resumo de seis páginas, sendo três de texto). D esconheço o quanto da proposta será adotada no plano. Com esta ressalva, responderei às suas perguntas tentando comparar as duas posições, na medida do possível.

\section{E m que consiste este plano? Q uais suas metas e objetivos? Q uais seus aspectos mais importantes?}

J osé J uliano - Para facilitar, utilizarei a palavra "Proposta" quando me referir ao trabalho desenvolvido pelo Plínio e equipe, e a sigla "PN RA" para identificar a posição oficial. A Proposta de PN RA tem as seguintes características: foi concebida com a finalidade de fornecer ao governo elementos para a decisão de implantar a R eforma Agrária. D essa forma, constitui-se na primeira fase de um processo de planejamento, com o objetivo de estimar o público da Reforma, 0 estoque de terras disponível, a renda esperada para os assentados, os custos para o governo e as metas. A Proposta também discute a forma de organização dos 
futuros assentamentos, impactos esperados da reforma e algumas medidas fundamentais para que o PN RA se torne realidade. 0 objetivo principal da Proposta era iniciar um processo que, de fato, levasse o governo Lula a uma política com potencial de impacto significativo na desconcentração fundiária do País e, assim, confrontasse as forças do latifúndio que sempre impediram políticas desse tipo. As metas apresentadas no documento são as seguintes:

M eta 1 - D otar um milhão de famílias de trabalhadores pobres do campo com uma área de terra suficiente para obter, com seu trabalho, uma renda compatível com uma existência digna. Essa meta seria cumprida em quatro anos (2004 a 2007), com duzentas mil famílias assentadas anualmente, nos três primeiros anos, e quatrocentas mil no último ano do Plano Plurianual de Investimentos (PPA).

M eta 2 - Assegurar às famílias beneficiárias das ações de reforma agrária e dos agricultores familiares uma renda bruta mensal equivalente a três salários mínimos e meio, composta de renda monetária e valor de autoconsumo.

M eta 3 - Criar 2,5 milhões de postos de trabalho permanentes no setor reformado.

M eta 4 - Consolidar os assentamentos de reforma agrária já constituídos, mas que ainda não atingiram a meta de renda fixada para os novos assentamentos.

M eta 5 - Regularizar os quilombos.

M eta 6 - Regularizar a situação dos agricultores ribeirinhos desalojados para a construção de barragens.

M eta 7 - Reassentar, fora do perímetro das áreas indígenas, posseiros com posses de até 50 ha, atualmente estabelecidos naquelas áreas.

M eta 8 - E fetuar o levantamento georeferenciado do território nacional, a fim de sanear definitivamente os títulos de propriedade de terras do país.

M eta 9 - Atender aos assentados e aos agricultores familiares das áreas de reordenamento fundiário e desenvolvimento territorial com assistência técnica, extensão rural e capacitação.

M eta10 - L evar, por meio do Plano de Safra, o crédito agrícola e a garantia de preços mínimos aos assentados e agricultores familiares. Esta meta é fundamental para viabilizar o nível de renda prevista. A eficácia da política depende também de outra sugestão da proposta, qual seja, assentar e atuar adensando os agricultores assentados e atuais agricultores familiares em territórios, constituindo áreas reformadas.

Além dos pontos já mencionados, a Proposta previa: a mudança do critério de pagamento da terra desapropriada, indexando o TD A a um índice de preço da terra local e não à taxa referencial do mercado financeiro mais 6\%, como é feito desde o governo Collor, premiando o latifúndio improdutivo; atualização no Cadastro de I móveis com a aplicação de novos índices de produtividade usados pelo Incra para definir se a propriedade é produtiva ou improdutiva. O s índices utilizados no presente são da década de 1970 e existem pesquisas concluídas, 
contratadas pelo Incra, atualizando esses índices. A sua aplicação implicaria a verificação da existência de mais terras improdutivas. Esses dois pontos, somados a um número expressivo de assentados por desapropriação de terras improdutivas - na proposta a desapropriação constitui o instrumento principal da Reforma Agrária - e a política agrícola dirigida especificamente para o público da política agrária (assentados e agricultores familiares) são fundamentais para uma R eforma Agrária massiva e eficiente. E les se constituem em bandeiras de luta porque implicam disputa de recursos dentro do governo e confronto com os interesses do latifúndio.

A Proposta também apresenta uma estimativa de custos, para quatro anos, de $R \$ 24$ bilhões e estimativas de necessidade de terras entre 35 e 46 milhões de hectares, depende do tamanho do lote utilizado. É importante ressaltar que R \$11 bilhões desse custo referem-se ao pagamento das terras e devem ser pagos em TD A e resgatados a longo prazo.

\section{E o que disso tudo foi incluído no Plano do G overno L ula?}

J oæéJ uliano- O PN RA anunciado pelo governo - documento "Plano N acional de Reforma Agrária" - apresenta as seguintes metas: a) quatrocentas mil famílias assentadas; b) meio milhão de famílias com posses regularizadas; c) 130 mil famílias beneficiadas pelo crédito fundiário; d) recuperar a capacidade produtiva e a viabilidade econômica dos atuais assentamentos; e) criar 2.075 novos postos permanentes de trabal ho no setor reformado; f) cadastramento georeferenciado do território nacional e regularização de 2,2 milhões de imóveis rurais; g) reconhecer, demarcar e titular áreas de comunidades quilombolas; h) garantir o reassentamento dos ocupantes não índios de áreas indígenas; i) promover igualdade de gênero na Reforma agrária; j) garantir assistência técnica e extensão rural, capacidade, crédito e políticas de comercialização a todas as famílias das áreas reformadas; k) universalizar o direito à educação, à cultura e à seguridade social nas áreas reformadas.

O s assentamentos planejados estão assim distribuídos: trinta mil famílias em 2003; 115 mil famílias por ano em 2004 e 2005; 140 mil famílias em 2006. 0 documento também prevê o assentamento de 150 mil famílias para 2007.

Trata-se, portanto, de um plano muito menos generoso que a Proposta no que diz respeito ao número de famílias assentadas. Essa timidez implica impacto muito menor na concentração fundiária. 0 documento fonte destas informações não apresenta previsão de custos e estimativas de tamanho de lote. Também não esclarece sobre a preferência que deve ser dada aos trabalhadores acampados, que no caso da Proposta deveriam ser assentados no primeiro ano de vigência do Plano.

0 documento governamental dá ênfase às ações de regularização e crédito fundiário. $\mathrm{N}$ a Proposta, essas ações são consideradas apenas como complementares. A regularização não é instrumento básico de reforma agrária, embora possa 
ser utilizada para regularizar pequenas posses em áreas reformadas. Esse caráter complementar também ocorre com o instrumento "crédito fundiário" ou "compra de terras". É interessante lembrar que no passado - último governo militar e governo FH C - esses instrumentos foram utilizados para justificar políticas chamadas de reforma agrária e nada resolveram, mantendo a estrutura agrária.

D esconhece-se também o quanto de recursos serão destinados à reforma, mas tudo indica que houve restrição da área econômica. 0 utra questão relevante é que ainda não se sabe se o governo adotará as mudanças quanto ao TD A e aos índices que medem a produtividade.

Q ual a importância de o plano ser discutido com a população brasileira? D e que maneira a sociedade pode contribuir para a sua aprovação?

J œé J uli ano - A importância do debate é fundamental. Discutir o PNRA com a sociedade organizada e com as superintendências do I ncra nas regiões estava previsto na Proposta como o passo seguinte do planejamento ou da execução do PNRA. Esse debate teria a função de construir os planos regionais e estaduais. $\mathrm{N}$ ão sei como o governo agirá a respeito.

Se o PN RA for realmente um plano de reforma agrária é evidente que confrontará os interesses do latifúndio. M esmo com meta muito mais tímida, se o governo alterar a indexação do TD A e aplicar os novos índices de produtividade ao cadastro, entendo que haverá confronto de interesses. A pressão da sociedade será fundamental para que o executivo adote essas medidas. D epende apenas dele.

\section{Q uais são as medidas que o plano contém que assegurem não só a conquista da terra, mas também a permanência nela?}

J œéJ uli ano- Para responder a essa pergunta, vou destacar parte do sumário que fizemos sobre a Proposta. "O Plano estima os investimentos específicos na R eforma Agrária para a obtenção de terras, construção da moradia e implantação do assentamento. Essas são as ações que demandam recursos orçamentários, seja para novos assentamentos, a base de R \$ 24 mil por família assentada, seja para antigos assentamentos, onde se investirá para sua recuperação. N esse último caso, não haverá gastos nas categorias de obtenção e construção de moradia, mas tão-somente para completar adequadamente sua implantação. E sse investimento terá uma parcela que será paga em vinte anos pelo assentado - terra e moradia -, e outra não ressarcível - os gastos de implantação -, que são de responsabilidade do Estado e se caracterizam como investimentos de usufruto coletivo.

Para pagar esses investimentos a longo prazo, bem como realizar novos que consolidem 0 assentamento, 0 assentado precisa gerar um excedente (renda bruta, deduzidos gastos de consumo básico e produção), que Ihe permita construir um horizonte de desenvolvimento para si e para as novas gerações.

$\mathrm{N}$ esse sentido, o Plano contempla um conjunto de ações conexas à R eforma Agrária no âmbito do Plano de Safra e das políticas sociais, cujo objetivo 
central é garantir aos novos assentados, assim como aos antigos beneficiados pela nova estratégia, a obtenção de uma renda bruta familiar de 3,5 salários mínimos equivalente ao ano. Para garantir essa meta combinam-se arranjos de política agrícola (compra garantida), produção de autoconsumo, venda em mercados locais, por um lado; e outras estratégias não-agrícolas de percepção de renda, em que se recorrerá a to dos os mecanismos de garantia de renda mínima já assegurados na política social."

0 documento governamental apresenta como meta garantir essas políticas para as famílias das áreas reformadas. E spero que o que foi sugerido na proposta seja adotado pelo M DA. N ovamente, cabe a ressalva que desconheço as previsões de gastos e renda que farão parte do PNRA oficial.

A população brasileira mostra que é a favor da reforma agrária, porém, até agora o governo discute, pauta e coloca em primeiro plano outras reformas, como a da previdência. Você acha que com o lançamento e discussão desse plano o cenário irá mudar?

José Juliano - Para que isto ocorra, é preciso que o governo esclareça realmente qual será o Plano. É preciso que ele mostre à sociedade que não se trata de uma mera continuidade do que vinha sendo feito. É preciso que o PN RA confronte os estrangulamentos oriundos dos interesses latifundiários, como é 0 caso das regras de desapropriação e pagamento da terra. É preciso que o governo indique as alterações legais necessárias. Afinal, é imprescindível que o governo informe à sociedade que tem um Plano bem estruturado, quais serão os próximos passo s e que alocará os recursos necessários.

0 que me parece relevante é que, apesar da timidez das metas de assentamentos, o governo comprometeu-se com metas quantitativas e qualitativas que serão alvo de cobrança por parte dos movimentos sociais.

Por ora, não existe o debate na sociedade. $\mathrm{H}$ á um silêncio na mídia. É preciso que o governo defina claramente o que vai fazer.

Q uais as circunstâncias históricas e conjunturais que diferem os dois planos nacionais de reforma agrária elaborados? $Q$ uais os fatores que impediram que o primeiro fosse aprovado e implantado?

Jośjuliano- 0 primeiro PN RA foi proposto, discutido, modificado muitas vezes, reduzido em suas pretensões e, finalmente, aprovado. Todavia, sua implantação foi pífia. O Plano foi conseqüência do acordo político que levou o país à redemocratização, depois de tantos anos de ditadura militar. A proposta e a discussão do Plano provocaram uma forte reação da direita latifundiária, organização da U DR etc. N ão podemos esquecer que essa direita também fazia parte do governo, fato evidente, dada a composição política de então. Essa participação de forças políticas retrógradas foi uma constante durante todo o período pós-ditadura. Por outro lado, os movimentos sociais não apresentavam força e organização necessárias para o confronto que ocorreu. 


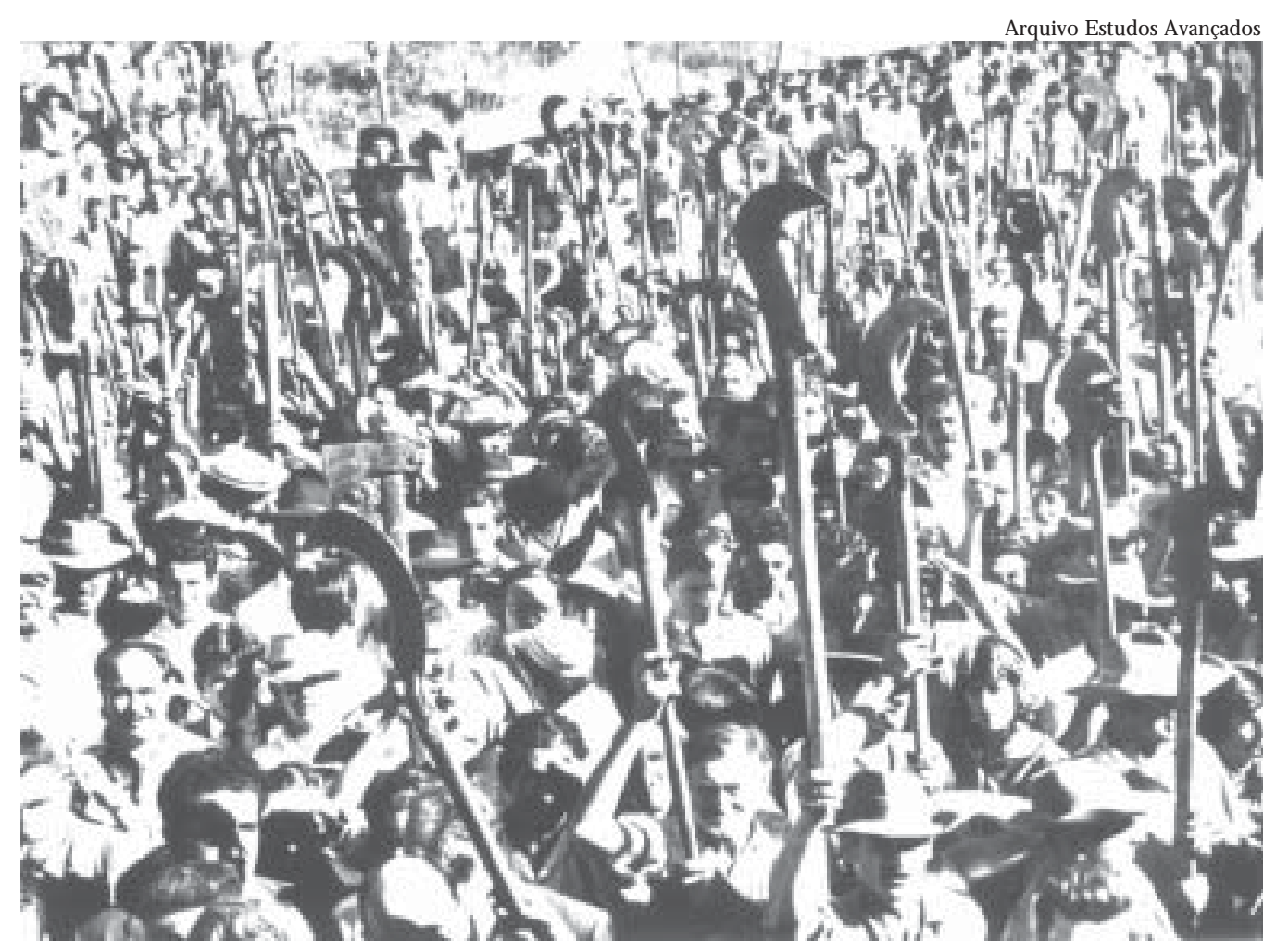

M anifestação de trabalhadores rurais sem-terra no R io Grande do Sul, em 1962.

Q uanto ao atual Plano, vejo que existem três diferenças significativas. A primeira refere-se à existência de movimentos sociais muito mais fortes e organizados. 0 sucesso de uma intervenção de profundidade na estrutura agrária depende da capacidade de pressão dos movimentos. A pesar de toda campanha de criminalização dos movimentos - com destaque para o M ST - eles estão muito mais fortes e organizados e vão cobrar o governo Lula. A união dos movimentos camponeses vista no Fórum de Brasília é fundamental para a implantação da política de Reforma Agrária. A segunda diferença diz respeito às significativas mudanças ocorridas na sociedade brasileira desde meados dos anos 1980. Falo aqui do processo de mundialização financeira da economia em geral e das transformações ocorridas no campo com o crescimento, desnacionalização e concentração de capitais no chamado agronegócio. Esse processo serve à acumulação de capital e implica destruição de postos de trabalho, exclusão e maior concentração de renda. E ntendo que para ter a sociedade a favor da reforma agrária é preciso conscientizá-la sobre essa situação e sobre os efeitos positivos da Reforma na geração de empregos e desconcentração da propriedade e da renda.

A terceira diferença positiva, assim o espero, apesar das contradições do poder executivo, refere-se a uma conjuntura política caracterizada pela el eição de um governo de origem popular e que, durante a campanha, comprometeu-se a fazer uma reforma agrária de fato. No documento de campanha "Vida D igna no Campo", o candidato Lula comprometeu-se com a reforma. Espero que o seu 
governo não renegue suas origens e compromissos. U m bom começo seria alterar a postura submissa em relação à política econômica.

\section{Q ual a necessidade de se encaminhar ao governo um Plano $\mathrm{N}$ acional de R eforma Agrária?}

J oséJ uliano - $O$ encaminhamento do PNRA à presidência da República e a sua aceitação significa o compromisso do governo com uma política agrária de longo prazo. Ele terá que destinar recursos para a Reforma Agrária no Plano Plurianual de Investimentos (PPA) e liberar os recursos necessários anual mente. Se não o fizer, a existência do PNRA possibilitará a cobrança da sociedade em geral e dos movimentos sociais em particular.

\section{De que forma o Plano discute questões como educação, agroecologia e transgênicos?}

José Juliano - Tanto na Proposta como no documento do governo existe o compromisso com o acesso à educação, saúde e seguridade social. N a Proposta considera-se que deve haver uma ação integrada entre os ministérios responsáveis para que esses direitos cheguem aos beneficiários da reforma agrária.

A Proposta e o PNRA não discutem as questões da agroecologia e dos transgênicos. Falando pela Proposta, cabe-me esclarecer que a decisão sobre a organização do assentamento (coletivo, lotes individuais ou misto) caberia aos assentados, que teriam até três anos para decidir. 0 mesmo ocorre com o que plantar e com a adoção de sistemas de plantio, eles seriam fruto da decisão dos assentados.

0 governo afirma que não possui recursos para a realização da $R$ eforma Agrária no país. Você acha que esse argumento pode inviabilizar o plano ou fazer com que ele acabe na gaveta?

J œé J uliano - Essa possibilidade existe. 0 argumento da falta de recursos deve ter sido decisivo para a não adoção da meta de um milhão de famílias assentadas, como previa a nossa Proposta. Essa decisão, em minha opinião, é lamentável porque tira muito do caráter massivo do Plano e mostra a postura submissa do governo frente às exigências dos organismos internacionais (superávit primário etc.). Contudo, o governo comprometeu-se com metas quantitativas e terá que alocar recursos para cumpri-las. Além disso, terá que fortalecer o I ncra como órgão executor da R eforma. Se não o fizer, o PN RA será inviabilizado. Se isso acontecer, mostrará que a prioridade para a reforma não passa de retórica e se igual ará aos governos passados. Se isso vier a ocorrer, o governo terá que enfrentar a cobrança da sociedade.

Q ual deve ser o papel dos movimentos sociais de luta pela terra na atual conjuntura? E a relação entre governo e movimento social?

J oséj uliano- Tenho dúvidas quanto à existência de conjuntura favorável a uma reforma agrária que mereça essa denominação. $\mathrm{O}$ u seja, que desconcentre a terra e a renda e que enfrente os interesses do latifúndio. Esse é um assunto no qual o governo Lula será testado. 
Se as verbas necessárias forem alocadas, se o Incra for reestruturado, se as metas forem cumpridas, se o governo enfrentar o latifúndio, acredito que os movimentos devem sustentar as ações governamentais nos embates que virão. Todavia, mesmo essa sustentação deverá ser caracterizada pela independência dos movimentos em relação ao governo e nunca pela cooptação.

M esmo no contexto que você destaca, não podemos esquecer que a pressão dos movimentos é que empurra o governo para assumir responsabilidades na questão agrária. 0 motor da reforma não é o governo, são os movimentos. 0 processo ocorrido para se chegar ao PN RA do governo Lula é um exemplo desse fato. Vejo a independência e, por conseqüência, a pressão dos movimentos como fundamentais.

\section{Como o Plano pode garantir o aumento de emprego e de renda nas áreas rurais?}

J œéJ uliano - É muito importante que o PN RA não repita os assentamentos dispersos dos governos passados, ou seja, que procure estabelecer áreas reformadas. E sse aden samento propiciará eficiência e eficácia para as políticas de apoio à produção e para as ações de educação, saúde e seguridade. É fundamental que a experiência do Plano Safra deste ano seja permanente.

Repetindo o que já foi dito sobre a Proposta: "para garantir essa meta ( renda) combinam-se arranjos de política agrícola (compra garantida), produção de autoconsumo, venda em mercados locais, por um lado; e outras estratégias não-agrícolas de percepção de renda, em que se recorrerá a todos os mecanismos de garantia de renda mínima já assegurados na política social". A execução dessa política é de enorme importância para não repetir o que ocorreu no governo passado: assentamentos com miséria e destruição da produção familiar conseqüente do avanço e transformações do agronegócio e insuficiên-cia da política agrícola destinada aos assentados e agricultores familiares.

\section{Q uais as medidas administrativas previstas no Plano para assentar to- das as famílias sem terra?}

J œé Juliano - O PNRA do governo e mesmo a nossa proposta não têm a capacidade de assentar todas as famílias sem terra. 0 governo reduziu a meta da proposta, mas mesmo a nossa, propondo um milhão de famílias assentadas, não assentaria to das as famílias sem terra. Em nosso cálculo sobre o público potencial da reforma, chegamos a um mínimo de 3,2 milhões de famílias (pobreza extrema) e um teto de cerca de seis milhões de famílias compostas de trabalhadores agrícolas sem-terra ou cujos estabelecimentos agropecuários não contam com terra suficiente para a sua manutenção.

Para o atual Plano, creio que as medidas devem ser as seguintes: alocação dos recursos; elaboração dos planos regionais e locais; alteração das regras de remuneração dos TD As; atualização do cadastro de imóveis e aplicação dos novos índices de produtividade; priorização do georeferenciamento das futuras áreas reformadas; fortalecimento do Incra. 
O Plano tinha como meta o assentamento de um milhão de famílias, mas a reformulação feita por Miguel Rosseto aponta 0 assentamento de 355 mil famílias até 2006. N a sua opinião, o governo está sendo prudente (ao assentar famílias de acordo com as verbas), ou tímido (no sentido de se preservar) e não comprar briga com a elite latifundiária?

J oæéj uli ano- Primeiramente é preciso esclarecer que a meta governamental é de quatrocentas mil famílias para o período do mandato (2003/ 2006), mais 150 mil famílias previstas para 2007.

Q uanto á resposta à sua pergunta - se foi prudência ou timidez -, creio que foi timidez. A prioridade e a necessidade da reforma justificam os custos. Relembro que na Proposta chegamos a um custo total de 24 bilhões para os quatro anos, incluindo onze bilhões destinados à compra de terra que pode ser pago em TD A. É evidente que quanto menor for o número de famílias assentadas, menor será a necessidade de terra e menos incômodo se causa aos interesses do latifúndio. Todavia, poderemos verificar se o governo está disposto a enfrentar esses interesses quando definir a sua postura frente à necessidade de alteração das regras do TD A, atualização do cadastro (inclusive utilização de novos índices de produtividade) e enfrentamento da grande grilagem de terras.

As terras griladas, usadas para trabalho escravo e aquelas que prejudicam o meio ambiente, caso fossem desapropriadas, seriam suficientes para a reforma?

J osé J uliano - D urante as discussões para a elaboração da Proposta procuramos estimar o estoque de terras para a reforma agrária e verificamos que não há falta delas.

Em resumo, as nossas estimativas chegaram aos seguintes números: 120 milhões de hectares de terras improdutivas, considerando as propriedades maiores que quinze módulos fiscais cadastradas no I ncra; 170,9 milhões de hectares de terras devolutas incluindo posses legalizáveis por estarem dentro do limite de 100 ha; 110, 9 milhões de ha de terras devolutas, excluindo as terras legalizáveis por ações de regularização; 4,4 milhões de terras públicas. Q uando se analisam esses dados, nota-se que metade do país está cadastrado e que a outra metade, excluindo-se as áreas do I bama, Funai e públicas, ainda apresenta um enorme vazio que certamente é objeto de grilagem.

Especificamente quanto ao aspecto ambiental, uma idéia que foi discutida visava a criar mecanismos que atinjam o valor dos índices de produtividade - para pior - quando esse aspecto da função social não for cumprido.

No que se refere ao trabalho escravo, a nossa posição é que esse caso deve ser tratado da mesma forma que se trata o plantio de droga, a terra deve ser confiscada para fins de reforma agrária. 